This is the peer reviewed version of the following article: Lewis, S. P., Heath, N. L., Hasking, P. A., Whitlock, J. L., Wilson, M. S., \& Plener, P. L. (2019). Addressing self-injury on college campuses: Institutional recommendations. Journal of College Counselling, 22(1), 70-82. doi.org/10.1002/jocc.12115

\title{
Addressing Self-Injury on College Campuses: Institutional Recommendations
}

Nonsuicidal self-injury is a significant concern on college campuses. Hence, the authors, the International Consortium on Self-Injury in Educational Settings, offer the current position paper. First, the authors review current research in the field. Next, they discuss considerations for colleges' institutional-wide response to self-injury, including the role of and recommendations for relevant stakeholders (students, residence staff, mental health professionals) who directly and indirectly support students who self-injure. Guidelines for response and suggested resources are also presented.

Keywords: nonsuicidal self-injury, institutional response, treatment options, college students, university students

Nonsuicidal self-injury (NSSI) refers to the intentional damage of one's body tissue (e.g., cutting, burning, self-hitting) in the absence of suicidal intent (International Society for the Study of Self-Injury, n.d.). Over the past several years, NSSI has emerged as a critical and grow- ing mental health concern among college/university students (e.g., Heath, Toste, Nedecheva, \& Charlebois, 2008; Lewis \& Arbuthnott, 2012; Whitlock, Eckenrode, \& Silverman, 2006). Indeed, there has been a substantial growth of research concerning NSSI in college populations (Brackman, Morris, \& Andover, 2016; Heath et al., 2008; Lewis \& Arbuthnott, 2012; Taliaferro \& Muehlenkamp, 2015; Whitlock et al., 2006). For example, according to a search conducted in Web of Science, the number of peerreviewed articles published annually in this area has grown 10-fold from 2007 to 2015 . Notwithstanding the growth of empirical knowledge in this area, NSSI is the subject of numerous myths and misconceptions (Lewis \& Heath, 2013; Lewis, Mahdy, Michal, \& Arbuthnott, 2014). Moreover, college professionals report witnessing an increase in NSSI- 
related concerns in their work with students yet, unfortunately, report insufficient knowledge and/or confidence to effectively address or manage NSSI (Whisenhunt et al., 2015; Whitlock et al., 2011).

Although there have been a number of efforts to summarize key findings pertinent to NSSI among college populations or to provide resources for college mental health professionals (MHPs; e.g., Lewis \& Arbuthnott, 2012), we know of no article that attempts to address NSSI at an institutional level. In particular, there is a need to consider how all major stakeholders (e.g., students, residence hall staff) can play a role in addressing NSSI on campuses. As an initial step in this regard, it is essential that key stakeholder roles be articulated and resources provided for each.

To address this pressing need, we, the International Consortium on Self- Injury in Educational Settings, an interdisciplinary and international group of leading researchers and clinicians in the field whose primary goals are to address and prevent NSSI in educational settings (Hasking et al., 2016), offer the current position paper. Specifically, we considered the process of an institutional response to self-injury to provide recommendations based on the most up-to-date empirical literature and our collective expertise.

Following the above, this position paper is divided into two sections. The first summarizes the most recent research concerning NSSI among college students, with the goal of fostering a general understanding of NSSI among college professionals. This includes key demographic information, biological underpinnings, and NSSI risks and functions, as well as the link between NSSI and suicidal behavior. In the second section, we focus on effective institutional responses to NSSI, with an emphasis on the provision of 
This is the peer reviewed version of the following article: Lewis, S. P., Heath, N. L., Hasking, P. A., Whitlock, J. L., Wilson, M. S., \& Plener, P. L. (2019). Addressing self-injury on college campuses: Institutional recommendations. Journal of College Counselling, 22(1), 70-82. doi.org/10.1002/jocc.12115

NSSI resources intended to increase NSSI literacy and how to best respond to students who self-injure. To do this, we drew on existing recommendations to address NSSI applied to college MHPs (e.g., Lewis \& Arbuthnott, 2012), more general guidelines for addressing NSSI (e.g., Washburn et al., 2012), and our collective expertise and experience addressing NSSI in educational settings (e.g., Hasking et al., 2016).

To this end, we highlight critical issues in college responses to self-injury, followed by recommendations for directly supporting students who engage in NSSI as well as recommendations for fellow students (e.g., friends, romantic partners) providing indirect support. In addition, guidelines are provided for those individuals who serve in a more formalized, supportive role within the institution-namely, residence hall staff, peer support networks (PSNs), and MHPs. We elected to limit the focus on the provision of quality resources to key on-campus stakeholders versus offering guidance on specific policies and protocols. Indeed, the implementation of protocols necessitates empirical research to inform such efforts. Given that research in this regard is scant, we call for such efforts because they would complement the current paper's aims and enhance how colleges address NSSI among students.

\section{Understanding NSSI Among College Students}

\section{Demographics}

Although the most common period of onset for NSSI is middle adolescence, the second most frequent time of onset occurs between the ages of 17 and 24 years, suggesting that the college years are a risk period for beginning self-injury (Lewis \& Arbuthnott, 2012; Whitlock et al., 2006). Reported lifetime rates of NSSI in college populations vary substantially, ranging from 7\% to 38\% (Gratz, Conrad, \& Roemer, 2002; Hasking, Momeni, 
Swannell, \& Chia, 2008; Heath et al., 2008; Hoff \& Muehlenkamp, 2009; Klonsky \& Olino, 2008; Kuentzel, Arble, Boutros, Chugani, \& Barnett, 2012; Whitlock et al., 2006, 2011; Wilcox et al., 2012). In a large meta-analysis, Swannell, Martin, Page, Hasking, and St John (2014) estimated a pooled lifetime prevalence of $20 \%$ among college students. Results concerning possible gender differences in rates of lifetime NSSI among college students have been contradictory, with evidence both for women reporting higher rates (e.g., Whitlock et al., 2011) and for an absence of gender differences (e.g., Lewis \& Arbuthnott, 2012; Whitlock et al., 2006). Rates for NSSI engagement in the past year tend to range from $2 \%$ to 14\% (Kuentzel et al., 2012; Serras, Saules, Cranford, \& Eisenberg, 2010; Whitlock et al., 2006; Wilcox et al., 2012).

\section{Biology}

The neurobiological background of NSSI has recently been explored, primarily among adults with borderline personality disorder (BPD). Individuals with BPD show an elevated pain threshold and altered activation in the limbic system and other regions of the pain matrix in response to physical pain (Bonenberger, Plener, Groschwitz, Grön, \& Abler, 2015; Koenig, Thayer, \& Kaess, 2016; Reitz et al., 2015). The pain threshold seems to return to normal levels after the individual reports stopping NSSI for at least 6 months (Ludäscher et al., 2009). However, understanding of the neurobiological correlates of NSSI in the general population (i.e., those without BPD) remains in its infancy.

\section{Risk Factors}

Although there has been a growing body of research examining correlates of NSSI, there has been substantially less investigation into risk factors that predict NSSI over time. Nevertheless, certain factors are consistently found to associate with NSSI, including 
This is the peer reviewed version of the following article: Lewis, S. P., Heath, N. L., Hasking, P. A., Whitlock, J. L., Wilson, M. S., \& Plener, P. L. (2019). Addressing self-injury on college campuses: Institutional recommendations. Journal of College Counselling, 22(1), 70-82. doi.org/10.1002/jocc.12115

psychological distress, symptoms of depression and anxiety disorders, emotion regulation difficulties, self-criticism, poor interpersonal relationships (e.g., current and past attachment difficulties), substance abuse, history of abuse, sexual orientation (bisexual or questioning), disordered eating behaviors, and/or negative perceptions of the body, as well as a number of psychological disorders, such as major depression, anxiety disorders (e.g., posttraumatic stress disorder), eating disorders, and BPD (Gollust, Eisenberg, \& Golberstein, 2008; Hasking et al., 2008; Lewis \& Arbuthnott, 2012; Serras et al., 2010; Taliaferro \& Muehlenkamp, 2014, 2015; Whitlock et al., 2006). Thus, there is no single clear risk factor for NSSI. Rather, there are a number of risk factors that associate with NSSI. It is important to recognize that young adults who are subject to significant stress (e.g., sexual minority stress, trauma) and/or struggling with psychosocial difficulties may be at risk for self-injury (Fox et al., 2015).

\section{Functions}

One of the most commonly reported reasons for self-injury is to obtain relief from overwhelming intense negative emotions that are perceived to be intolerable (i.e., to regulate emotions; Klonsky, 2007, 2009). A less common reason for self-injury may be to communicate pain or to attempt to manage a difficult interpersonal situation (Klonsky, 2007, 2009). Thus, although a commonly held view is that self-injury may be used to manipulate or influence others (e.g., attention seeking), this may be better understood as an attempt to cope with interpersonal difficulties (Lewis \& Heath, 2015). For example, it may be interpreted as manipulative when an individual self-injures in response to a significant other raising concerns in the relationship - that is, when the self-injury is due to the individual's inability to interpersonally communicate distress in other ways. Other, less frequently reported 
reasons include to engage in self-punishment and to diminish feelings of emotional numbness or depersonalization. The majority of people who self-injure report multiple reasons for NSSI, and their reasons may change or evolve over time (Klonsky, 2007, 2009;

Lewis \& Arbuthnott, 2012). It is therefore important to understand NSSI as an unhealthy coping behavior that serves a purpose for the individual in the absence of healthier coping strategies.

\section{NSSI and Suicide}

Motivationally, NSSI is distinct from suicidal behavior given that it is enacted without an explicit intent to die (Nock, 2010). Despite this important distinction, however, it is not uncommon for individuals who self-injure to report suicidal ideation or a past suicide attempt (e.g., Taliaferro \& Muehlenkamp, 2014, 2015). Indeed, a growing body of research has shown that NSSI represents a unique and robust factor involved in suicide risk (Glenn \& Klonsky, 2009; Klonsky, May, \& Glenn, 2013; Nock, Joiner, Gordon, Lloyd-Richardson, \& Prinstein, 2006; Whitlock et al., 2013). Furthermore, researchers have found that NSSI confers risk for suicidal ideation and behavior over time (Whitlock et al., 2013). Among the NSSI factors that may elevate risk for suicide are a longer standing NSSI history, use of multiple NSSI methods, and the reporting of no physical pain at the time of injury (e.g., Hamza, Stewart, \& Willoughby, 2012; Klonsky et al., 2013; Nock et al., 2006; Whitlock et al., 2013). In light of this, it is essential that responses to students who self-injure be informed and appropriate, with suicide risk assessment by MHPs as needed.

\section{Effective Responses to NSSI on College Campuses}

\section{Critical Issues in a College Response to NSSI}

College settings are unique in offering opportunities to provide services in the area of 
This is the peer reviewed version of the following article: Lewis, S. P., Heath, N. L., Hasking, P. A., Whitlock, J. L., Wilson, M. S., \& Plener, P. L. (2019). Addressing self-injury on college campuses: Institutional recommendations. Journal of College Counselling, 22(1), 70-82. doi.org/10.1002/jocc.12115

self-injury; to decrease stigma through enhanced awareness and understanding; and to improve individual, staff, and institutional responses to NSSI. In turn, this has the potential to increase help seeking and access to information about alternative supports for those who do not seek mental health services. However, ensuring that the college MHPs' training is consistent with current best practice in the field of NSSI is imperative (Klonsky, Muehlenkamp, Lewis, \& Walsh, 2011; Washburn et al., 2012).

A comprehensive approach to addressing NSSI on college campuses necessitates improving mental health literacy at all levels. Components of mental health literacy specifically related to NSSI can easily be incorporated into existing mental health promotion training programs, with an emphasis, as described in the following section, on understanding why students self-injure, how to effectively respond to students who self-injure, and appropriate referral pathways. However, there are several challenges specific to college settings when considering how to best address NSSI. For example, there is a lack of monitoring compared with school settings (Hasking et al., 2016). Moreover, increasing demands for mental health services often exceed available resources. As a result, colleges may need to use a multifaceted and nontraditional approach to effectively reach, respond to, and support students who engage in NSSI, as detailed in the following section.

Thus, the best approach to addressing NSSI on college campuses is to adopt a multitiered, campus-wide approach. Although mental health staff, such as counselors, psychologists, and/or psychiatrists, may be integrally involved in treatment, fellow students (e.g., friends, romantic partners), residence hall staff, and PSN personnel are also likely to encounter students who self-injure. Accordingly, it is important that these individuals be provided with resources to guide effective responding and referral for students who self- 
injure. To maximize the success of these efforts, college administration and management must recognize and support the need for such an approach.

\section{Recommendations for Effective Response}

Effective response to NSSI is best achieved when basic tenets (see Figure 1) are disseminated as widely as possible to fellow students, individuals with campus support roles, health services, and MHPs. These tenets are drawn from published guidelines and recommendations for use when interacting and building rapport with individuals who selfinjure (Klonsky \& Lewis, 2014; Klonsky et al., 2011; Walsh, 2006; Washburn et al., 2012). Specifically, this includes having a basic understanding of NSSI, knowing how to broach the topic, being able to respond effectively when talking about NSSI with students, providing appropriate referral options, and engaging in self-care, as well as being aware of recommended resources (see Appendix). The resources listed in the Appendix were selected on the basis of past research examining the quality of online NSSI material (Lewis et al., 2014) as well as literature highlighting and recommending several of these resources as a means to augment NSSI literacy and foster more effective responding to those who selfinjure (Hasking et al., 2016; Lewis, Heath, Michal, \& Duggan, 2012; Lloyd-Richardson, Lewis, Whitlock, Rodham, \& Schatten, 2015). Dissemination of effective response guidelines should occur through materials provided at orientation, mental health service websites, and all relevant mental health or student wellness activities and events. NSSI resources should pertain not only to those who self-injure but also to those who play an informal supportive role for these individuals (e.g., friends, romantic partners). Finally, for college personnel who have less involvement in student mental health, basic information about NSSI and appropriate resources/referral (see Appendix) should be incorporated in 
This is the peer reviewed version of the following article: Lewis, S. P., Heath, N. L., Hasking, P. A., Whitlock, J. L., Wilson, M. S., \& Plener, P. L. (2019). Addressing self-injury on college campuses: Institutional recommendations. Journal of College Counselling, 22(1), 70-82. doi.org/10.1002/jocc.12115

orientation and general mental health training.

Students who self-injure. Research has demonstrated that students who self- injure do not often seek help from MHPs and may talk about their self-injury only to a friend after some time (Rosenrot \& Lewis, 2018). Therefore, for those who self-injure, it is critical to make resources and materials about NSSI routinely available to students. This can occur via college mental health services (e.g., listing NSSI as one of several concerns that can prompt accessing services) and more generally by providing students with links to reputable recovery-oriented websites (e.g., via the mental health services page for a col- lege). For a list of recommended resources, see the Appendix. Students who self-injure should also have access to information about available on-campus mental health and crisis services.

Friends and romantic partners. In addition to resources for students who self-injure, it is important to offer resources to students who do not self-injure. Friends and romantic partners, in particular, may play a key role in supporting students who self-injure (Lewis \& Heath, 2015; Whitlock et al., 2006). Given differences in the dynamics of these relationships and the issues that may arise (e.g., concerns about intimacy and breakup in romantic relationships), resources and information, including details of effective responding (see Appendix), can be tailored to the various relationships (e.g., friends, romantic partner) that students may have with those who self-injure.

Campus staff with support roles. Within the college, there are many individuals who serve in a supporting role to students, including residence hall staff and PSNs in addition to college MHPs. Although the roles of these individuals differ substantially, all will encounter and interact with students who self-injure. Because of a lack of training, the potential for an uninformed and, consequently, poor first response is potentially high among non-MHPs. Thus, 
we recommend that all of these individuals be provided with information commensurate with their role, as described in the following sections. Furthermore, given that supporting students who engage in self-injury may be emotionally taxing, individuals who work in a supportive role with these students should be encouraged to be conscious of the need for self-care and be aware of services to support them as needed.

Residence hall staff. It is not uncommon in many countries for young people to attend colleges that require them to live independently for the first time, often, at first, in college residence halls. Given that research suggests that NSSI can be conceptualized as a strategy to obtain relief from negative emotional and cognitive experiences (Chapman, Gratz, \& Brown, 2006; Klonsky, 2007; Nock \& Prinstein, 2004), it is reasonable to expect that young people moving away from their familiar environments and traditional supports, and into college residence halls, may be at greater risk of engaging in NSSI (Dusselier, Dunn, Wang, Shelley, \& Whalen, 2005). In addition, there is some evidence to suggest that risk for NSSI may be elevated in contexts in which people live in close proximity to others who already self-injure; this is sometimes referred to as a social contagion effect (Jarvi, Jackson, Swenson, \& Crawford, 2013; Walsh, 2006; Whitlock, Eells, Cummings, \& Purington, 2009).

In conjunction with the high prevalence of NSSI among college students, providing training and support to residence hall staff, many of whom are themselves students, is warranted. Such training should focus on guidelines for effective NSSI response (see Figure 1) and information about resources (see Appendix), as well as discussion concerning a residence hall policy regarding referral of students who self-injure and response to possible NSSI contagion. Although we do not advocate for the referral of 
This is the peer reviewed version of the following article: Lewis, S. P., Heath, N. L., Hasking, P. A., Whitlock, J. L., Wilson, M. S., \& Plener, P. L. (2019). Addressing self-injury on college campuses: Institutional recommendations. Journal of College Counselling, 22(1), 70-82. doi.org/10.1002/jocc.12115

every incidence of NSSI to college counseling services, it is important for first responders to be aware of the limits of their experience, skills, and responsibilities in addressing NSSI. PSNs. Numerous college campuses offer peer-based support for the myriad difficulties that students may experience while enrolled in college. Although not available on all campuses, these PSNs offer students a platform in which to talk to other students in a confidential and supportive manner. Although they do not replace professional mental health care, they may serve as an important conduit to access appropriate professional care. Hence, it is vital that students who volunteer to work in PSNs be knowledgeable about NSSI and associated resources (see Appendix), as well as how to respond effectively (see Figure 1). To facilitate this undertaking, PSNs may wish to offer psychoeducational sessions and/or materials (e.g., websites, pamphlets) about NSSI and related mental health difficulties to their student volunteers.

Health services. Health services on college campuses represent a key stakeholder in which health professionals may encounter students who self-injure. This may involve interactions between students and nurses and physicians. Accordingly, it is important for these stakeholders to have sufficient NSSI literacy, as well as awareness of the recommended ways to initialize discussion about NSSI, how to assess NSSI, and referral sources (both on and off-campus). The tenets guiding effective responding to NSSI (see Figure 1) may therefore be useful. However, access to more comprehensive material, including recommended guidelines for NSSI assessment, may also have utility. For example, guidelines have been offered for NSSI assessment (Klonsky \& Lewis, 2014) and treatment (e.g., Klonsky et al., 2011; Washburn et al., 2012).

College MHPs. Currently, there are a number of publications outlining best practices for MHPs when responding to NSSI (Klonsky et al., 2011; Washburn et al., 2012), with some 
specific to college contexts (Lewis \& Arbuthnott, 2012; Whisenhunt et al., 2015). Although there are some challenges unique to college mental health services, overall, the response shares many commonalities with that of community- based MHPs to NSSI. In particular, first response, early assessment, assessment for treatment, and treatment itself are similar across settings and are well detailed elsewhere (Klonsky \& Lewis, 2014; Klonsky et al., 2011; Lewis \& Arbuthnott, 2012; Washburn et al., 2012). Challenges that are unique to the college MHP include limited resources, resulting in constraints around treatment volume, length, and intensity, as well as frequency of NSSI as a co-occurring concern for students. Furthermore, the high number of trainees providing service, many of whom have limited or no experience in responding to NSSI, is an additional difficulty in some college mental health services. Sharing suggested resources for MHPs as outlined in the Appendix is recommended as routine practice in mental health services.

College administration. The role of college administrators in the implementation of effective response to NSSI is vital. Accordingly, college administrators need to be made aware of the scope of NSSI on campus (e.g., its high rates, impact on student well-being, risk for suicide) as well as the significant likelihood of poor response in the absence of appropriate information and training. It is therefore essential for administration to commit resources and support to facilitate the dissemination of NSSI information to relevant stakeholders (as highlighted earlier). In our collective experience from working on and with colleges across several countries, although many college administrators are currently committed to addressing student mental health difficulties on campuses, NSSI is seldom, if ever, addressed in these efforts. We acknowledge the paucity of research in this area and recommend that efforts be made to better understand NSSI from the vantage point of 
This is the peer reviewed version of the following article: Lewis, S. P., Heath, N. L., Hasking, P. A., Whitlock, J. L., Wilson, M. S., \& Plener, P. L. (2019). Addressing self-injury on college campuses: Institutional recommendations. Journal of College Counselling, 22(1), 70-82. doi.org/10.1002/jocc.12115

college administrators.

\section{Conclusion}

Over the past several years, NSSI has emerged as a frequent and serious concern on college campuses (e.g., Lewis \& Arbuthnott, 2012; Whitlock et al., 2006). This signals the need for information about NSSI and how colleges, at an institutional level, can effectively respond to students who self-injure.

Drawing on the expertise of international researchers and clinicians in the area of NSSI in educational settings, this position paper critically analyzed key points of potential contact for students who engage in self-injury to create multifaceted outreach and support recommendations. Thus, this is the first article to (a) summarize the current NSSI knowledge base, (b) present recommendations that can be used by major college stakeholders who encounter students who self-injure, and (c) provide specific NSSI resources for these stakeholders. We believe that broad dissemination of response guidelines and resources for NSSI as outlined in the current position paper has the potential to significantly improve college response to self-injury. 


\section{References}

Bonenberger, M., Plener, P. L., Groschwitz, R. C., Grön, G., \& Abler, B. (2015).

Differential neural processing of unpleasant haptic sensations in somatic and affective partitions of the insula in non-suicidal self-injury (NSSI). Psychiatry Research: Neuroimaging, 234, 298-304. doi:10.1016/j.pscychresns.2015.10.013

Brackman, E. H., Morris, B. W., \& Andover, M. S. (2016). Predicting risk for suicide: A

preliminary examination of non-suicidal self-injury and the acquired capability construct in a college sample. Archives of Suicide Research, 20, 663-676. doi:10.1080/13811118.2016.1162247

Chapman, A. L., Gratz, K. L., \& Brown, M. Z. (2006). Solving the puzzle of deliberate self- harm: The experiential avoidance model. Behaviour Research and Therapy, 44, 371-394. doi:10.1016/j.brat.2005.03.005

Dusselier, L., Dunn, B., Wang, Y., Shelley, M. C., II, \& Whalen, D. F. (2005). Personal, health, academic, and environmental predictors of stress for residence hall students. Journal of American College Health, 54, 15-24. doi:10.3200/JACH.54.1.15-24

Fox, K. R., Franklin, J. C., Ribeiro, J. D., Kleiman, E. M., Bentley, K. H., \& Nock, M. K. (2015). Meta-analysis of risk factors for nonsuicidal self-injury. Clinical Psychology Review, 42, 156-167. doi:10.1016/j.cpr.2015.09.002

Glenn, C. R., \& Klonsky, E. D. (2009). Social context during non-suicidal self-injury indicates suicide risk. Personality and Individual Differences, 46, 25-29. 
This is the peer reviewed version of the following article: Lewis, S. P., Heath, N. L., Hasking, P. A., Whitlock, J. L., Wilson, M. S., \& Plener, P. L. (2019). Addressing self-injury on college campuses: Institutional recommendations. Journal of College Counselling, 22(1), 70-82. doi.org/10.1002/jocc.12115

doi:10.1016/j.paid.2008.08.020 Gollust, S. E., Eisenberg, D., \& Golberstein, E. (2008). Prevalence and correlates of self-injury among university students. Journal of American College Health, 56, 491-498. doi:10.3200/JACH.56.5.491-498

Gratz, K. L., \& Chapman, A. L. (2009). Freedom from self-harm: Overcoming selfinjury with skills from DBT and other treatments. Oakland, CA: New Harbinger.

Gratz, K. L., Conrad, S. D., \& Roemer, L. (2002). Risk factors for deliberate self-harm among college students. American Journal of Orthopsychiatry, 72, 128-140. doi:10.1037/0002-9432.72.1.128

Hamza, C. A., Stewart, S. L., \& Willoughby, T. (2012). Examining the link between nonsuicidal self-injury and suicidal behavior: A review of the literature and an integrated model. Clinical Psychology Review, 32, 482-495. doi:10.1016/j.cpr.2012.05.003

Hasking, P. A., Heath, N. L., Kaess, M., Lewis, S. P., Plener, P. L., Walsh, B. W., . . . Wilson, M. S. (2016). Position paper for guiding response to non-suicidal self-injury in schools. School Psychology International, 37, 644-663. doi: $10.1177 / 0143034316678656$

Hasking, P., Momeni, R., Swannell, S., \& Chia, S. (2008). The nature and extent of non suicidal self-injury in a non-clinical sample of young adults. Archives of Suicide Research, 12, 208-218. doi:10.1080/13811110802100957

Heath, N. L., Toste, J. R., Nedecheva, T., \& Charlebois, A. (2008). An examination of nonsuicidal self-injury among college students. Journal of Mental Health Counseling, 30, 137-156. doi:10.17744/mehc.30.2.8p879p3443514678 
Hoff, E. R., \& Muehlenkamp, J. J. (2009). Nonsuicidal self-injury in college students: The role of perfectionism and rumination. Suicide and Life-Threatening Behavior, 39, 576-587. doi:10.1521/suli.2009.39.6.576

International Society for the Study of Self-Injury. (n.d.). About self-injury: What is nonsuicidal self-injury? Retrieved from https://www.itriples.org/category/about-self-injury

Jarvi, S., Jackson, B., Swenson, L., \& Crawford, H. (2013). The impact of social contagion on non-suicidal self-injury: A review of the literature. Archives of Suicide Research, 17, 1-19. doi: 10.1080/13811118.2013.748404

Klonsky, E. D. (2007). The functions of deliberate self-injury: A review of the evidence. Clinical Psychology Review, 27, 226-239. doi:10.1016/j.cpr.2006.08.002

Klonsky, E. D. (2009). The functions of self-injury in young adults who cut themselves: Clarifying the evidence for affect-regulation. Psychiatry Research, 166, 260-268. doi:10.1016/j.psychres.2008.02.008 Klonsky, E. D., \& Lewis, S. P. (2014). Assessment of non-suicidal self-injury. In M. K. Nock (Ed.),

Oxford handbook of suicide and self-injury (pp. 337-351). New York, NY: Oxford University Press.

Klonsky, E. D., May, A. M., \& Glenn, C. R. (2013). The relationship between nonsuicidal self-injury and attempted suicide: Converging evidence from four samples. Journal of Abnormal Psychology, 122, 231-237. doi:10.1037/a0030278

Klonsky, E. D., Muehlenkamp, J. J., Lewis, S. P., \& Walsh, B. (2011). Nonsuicidal self- 
This is the peer reviewed version of the following article: Lewis, S. P., Heath, N. L., Hasking, P. A., Whitlock, J. L., Wilson, M. S., \& Plener, P. L. (2019). Addressing self-injury on college campuses: Institutional recommendations. Journal of College Counselling, 22(1), 70-82. doi.org/10.1002/jocc.12115

injury.

Cambridge, MA: Hogrefe. Klonsky, E. D., \& Olino, T. M. (2008). Identifying clinically distinct subgroups of self-injurers among young adults: A latent class analysis. Journal of Consulting and Clinical Psychology, 76, 22-27. doi:10.1037/0022006X.76.1.22

Koenig, J., Thayer, J. F., \& Kaess, M. (2016). A meta-analysis on pain sensitivity in selfinjury. Psy- chological Medicine, 46, 1597-1612. doi:10.1017/S0033291716000301

Kuentzel, J. G., Arble, E., Boutros, N., Chugani, D., \& Barnett, D. (2012).

Nonsuicidal self- injury in an ethnically diverse college sample. American Journal of Orthopsychiatry, 82, 291-297. doi:10.1111/j.1939-0025.2012.01167.x

Lewis, S. P., \& Arbuthnott, A. E. (2012). Nonsuicidal self-injury: Characteristics, functions, and strategies. Journal of College Student Psychotherapy, 26, 185-200. doi:10.1080/87568225.2012.685853 Lewis, S. P., \& Heath, N. L. (2013). Non-suicidal self-injury. CMAJ, 185, 505. doi:10.1503/cmaj.120969

Lewis, S. P., \& Heath, N. L. (2015). Nonsuicidal self-injury among youth. The Journal of Pediatrics, 166, 526-530. doi:10.1016/j.jpeds.2014.11.062

Lewis, S. P., Heath, N. L., Michal, N. J., \& Duggan, J. M. (2012). Non-suicidal selfinjury, youth, and the internet: What mental health professionals need to know. Child and Adolescent Psychiatry and Mental Health, 6, 1-9. doi:10.1186/17532000-6-13

Lewis, S. P., Mahdy, J. C., Michal, N. J., \& Arbuthnott, A. E. (2014). Googling self- 
injury: The state of health information obtained through online searches for selfinjury. JAMA Pediatrics, 168, 443-449. doi:10.1001/jamapediatrics.2014.187

Lloyd-Richardson, E. E., Lewis, S. P., Whitlock, J. L., Rodham, K., \& Schatten, H. T. (2015). Re- search with adolescents who engage in non-suicidal self-injury: Ethical considerations and challenges. Child and Adolescent Psychiatry and Mental Health, 9, 1-14. doi:10.1186/s13034-015-0071-6

Ludäscher, P., Greffrath, W., Schmahl, C., Kleindienst, N., Kraus, A., Baumgärtner, U., . . Bohus, M. (2009). A cross-sectional investigation of discontinuation of self-injury and nor- malizing pain perception in patients with borderline personality disorder. Acta Psychiatrica Scandinavica, 120, 62-70. doi:10.1111/j.1600-0447.2008.01335.x

Mental Health First Aid Australia. (2014). Non-suicidal self-injury: First aid guidelines. Retrieved from https://mhfa.com.au

Nock, M. K. (2010). Self-injury. Annual Review of Clinical Psychology, 6, 339-363. doi:10.1146/ annurev.clinpsy.121208.131258

Nock, M. K., Joiner, T. E., Jr., Gordon, K. H., Lloyd-Richardson, E., \& Prinstein, M. J. (2006). Non-suicidal self-injury among adolescents: Diagnostic correlates and relation to suicide attempts. Psychiatry Research, 144, 65-72. doi:10.1016/j.psychres.2006.05.010

Nock, M. K., \& Prinstein, M. J. (2004). A functional approach to the assessment of selfmutilative behavior. Journal of Consulting and Clinical Psychology, 72, 885890. doi:10.1037/0022- 006X.72.5.885 
This is the peer reviewed version of the following article: Lewis, S. P., Heath, N. L., Hasking, P. A., Whitlock, J. L., Wilson, M. S., \& Plener, P. L. (2019). Addressing self-injury on college campuses: Institutional recommendations. Journal of College Counselling, 22(1), 70-82. doi.org/10.1002/jocc.12115

Reitz, S., Kluetsch, R., Niedtfeld, I., Knorz, T., Lis, S., Paret, C., .. . Schmahl, C.

(2015). Incision and stress regulation in borderline personality disorder: Neurobiological mechanisms of self-injurious behaviour. The British Journal of Psychiatry, 207, 165-172. doi:10.1192/bjp.bp.114.153379

Rosenrot, S. A., \& Lewis, S. P. (2018). Barriers and responses to the disclosure of nonsuicidal self- injury: A thematic analysis. Counselling Psychology Quarterly. Advance online publication. doi:10. 1080/09515070.2018.1489220

Schmidt, U., \& Davidson, K. (2004). Life after self-harm: A guide to the future. New York, NY: Brunner-Routledge.

Serras, A., Saules, K. K., Cranford, J. A., \& Eisenberg, D. (2010). Self-injury, substance use, and associated risk factors in a multi-campus probability sample of college students. Psychology of Ad- dictive Behaviors, 24, 119-128. doi:10.1037/a0017210

Swannell, S. V., Martin, G. E., Page, A., Hasking, P., \& St John, N. J. (2014). Prevalence of non- suicidal self-injury in nonclinical samples: Systematic review, meta-analysis and meta-regression. Suicide and Life-Threatening Behavior, 44, 273-303. doi:10.1111/sltb.12070

Taliaferro, L. A., \& Muehlenkamp, J. J. (2014). Risk and protective factors that distinguish ado- lescents who attempt suicide from those who only consider suicide in the past year. Suicide and Life-Threatening Behavior, 44, 6-22. doi:10.1111/sltb.12046

Taliaferro, L. A., \& Muehlenkamp, J. J. (2015). Risk factors associated with self-injurious 
behavior among a national sample of undergraduate college students. Journal of American College Health, 63, 40-48. doi:10.1080/07448481.2014.953166

Walsh, B. (2006). Working with self-harming adolescents: A collaborative strengthsbased therapy approach [Review of the book Working with self-harming adolescents: A collaborative, strengths-based therapy approach (2nd ed.), by M. D. Selekman]. Psychiatric Services, 57, 1660. doi:10.1176/ ps.2006.57.11.1660

Walsh, B. W. (2012). Treating self-injury: A practical guide (2nd ed.). New York, NY: Guilford Press.

Washburn, J. J., Richardt, S. L., Styer, D. M., Gebhardt, M., Juzwin, K. R., Yourek, A., \& Aldridge, D. (2012). Psychotherapeutic approaches to non-suicidal self-injury in adolescents. Child and Adolescent Psychiatry and Mental Health, 6, 1-8. doi:10.1186/1753-2000-6-14

Whisenhunt, J. L., Chang, C. Y., Brack, G. L., Orr, J., Adams, L. G., Paige, M. R., , . . O’Hara, C. (2015). Self-injury and suicide: Practical information for college counselors. Journal of College Counseling, 18, 275-288. doi:10.1002/jocc.12020

Whitlock, J., Eckenrode, J., \& Silverman, D. (2006). Self-injurious behaviors in a college population. Pediatrics, 117, 1939-1948. doi:10.1542/peds.2005-2543

Whitlock, J., Eells, G., Cummings, N., \& Purington, A. (2009). Nonsuicidal self-injury in college populations: Mental health provider assessment of prevalence and need. Journal of College Student Psychotherapy, 23, 172-183. doi:10.1080/87568220902794366 
This is the peer reviewed version of the following article: Lewis, S. P., Heath, N. L., Hasking, P. A., Whitlock, J. L., Wilson, M. S., \& Plener, P. L. (2019). Addressing self-injury on college campuses: Institutional recommendations. Journal of College Counselling, 22(1), 70-82. doi.org/10.1002/jocc.12115

Whitlock, J., Muehlenkamp, J., Eckenrode, J., Purington, A., Baral Abrams, G., Barreira, P., \& Kress, V. (2013). Nonsuicidal self-injury as a gateway to suicide in young adults. Journal of Adolescent Health, 52, 486-492. doi:10.1016/j.jadohealth.2012.09.010

Whitlock, J., Muehlenkamp, J., Purington, A., Eckenrode, J., Barreira, P., Baral Abrams, G., . . Knox, K. (2011). Nonsuicidal self-injury in a college population: General trends and sex differ- ences. Journal of American College Health, 59, 691-698. doi:10.1080/07448481.2010.529626

Wilcox, H. C., Arria, A. M., Caldeira, K. M., Vincent, K. B., Pinchevsky, G. M., \& O'Grady, K. E. (2012). Longitudinal predictors of past-year non-suicidal self-injury and motives among college students. Psychological Medicine, 42, 717-726. doi:10.1017/S0033291711001814] 


\section{Tables and Figures}

\begin{tabular}{|c|c|c|}
\hline $\begin{array}{l}\text { Low-key calm } \\
\text { demeanor }\end{array}$ & $\begin{array}{c}\text { Non-judgmental and empathic } \\
\text { approach (devoid of over-reaction). }\end{array}$ & $\begin{array}{l}\text { [in a calm tone] It sounds like it has been } \\
\text { really hard for you lately. I appreciate that } \\
\text { you're willing to tell me about it. }\end{array}$ \\
\hline Respectful Curiosity & $\begin{array}{l}\text { Communicates a genuine interest in } \\
\text { understanding the student's } \\
\text { experience }\end{array}$ & $\begin{array}{l}\text { I'd like to understand better. Can you help me } \\
\text { to understand what self-injury does for you? }\end{array}$ \\
\hline $\begin{array}{l}\text { Use student's } \\
\text { language }\end{array}$ & $\begin{array}{l}\text { Validates student's experience and } \\
\text { conveys active listening. }\end{array}$ & $\begin{array}{l}\text { Student refers to "cutting" vs. self-injury. } \\
\text { Can you tell me more about your cutting? (vs. } \\
\text { using another term) }\end{array}$ \\
\hline $\begin{array}{c}\text { Focus on overall } \\
\text { wellbeing }\end{array}$ & $\begin{array}{l}\text { Avoids direct focus on the behavior, } \\
\text { which could reinforce it. Conveys a } \\
\text { broader concern for student. }\end{array}$ & $\begin{array}{l}\text { When students self-injure, there is usually a } \\
\text { lot going on. Maybe stress, relationship } \\
\text { difficulties, feeling down or alone. Can you tell } \\
\text { me what else is going on for you? }\end{array}$ \\
\hline $\begin{array}{l}\text { Validate self-injury } \\
\text { serves a purpose }\end{array}$ & $\begin{array}{l}\text { Conveys an understanding of the } \\
\text { student's reasons for self-injury; } \\
\text { validates the student's experience. }\end{array}$ & $\begin{array}{l}\text { It sounds like self-injury helps you to feel a bit } \\
\text { better when you're really struggling. I think } \\
\text { many students who have self-injured have } \\
\text { similar experiences. }\end{array}$ \\
\hline
\end{tabular}

\section{FIGURE 1}

Basic Tenets for Treating Nonsuicidal Self-Injury 